CLINICAL STUDY

\title{
Herpesvirus type 7 infection may play an important role in individuals with a genetic profile of susceptibility to Graves' disease
}

\author{
Janaina Luisa Leite, Natassia Elena Bufalo, Roberto Bernardo Santos ${ }^{1}$, João Hamilton Romaldini ${ }^{1}$
} and Laura Sterian Ward

Laboratory of Cancer Molecular Genetics, Faculty of Medical Sciences School, State University of Campinas (Unicamp), PO Box 6111, Campinas, São Paulo, Brazil and ${ }^{1}$ Division of Endocrinology, Department of Medicine, Catholic University of Campinas, Campinas, São Paulo, Brazil

(Correspondence should be addressed to L S Ward; Email: ward@fcm.unicamp.br)

\begin{abstract}
Objective: An inherited profile of genes related to the response to aggressive environmental factors such as viruses and chemicals may be related to an increased susceptibility to Graves' disease (GD). Design and methods: This prospective case-control study was designed to examine the relationship between human herpesviruses (HHV) infection, determined by circulating DNA; tumour protein p53 (TP53) apoptotic ability; and detoxification system genes, and GD. We studied 280 confirmed GD patients paired to 284 controls with respect to environmental exposure. Exclusion criteria included medications that could interfere with thyroid function evaluation and a recent history of viral and bacterial infections. Results: A stepwise regression analysis adjusted for age, gender, and ethnicity established the inheritance of glutathione S-transferase pi 1 (GSTP1) (odds ratio $(\mathrm{OR})=3.423 ; 95 \%$ confidence interval $(C I)=2.120-5.527 ; P<0.001)$ and cytochrome P450, family 1 , subfamily A, polypeptide $1(C Y P 1 A 1)$ variants $(\mathrm{OR}=1.649 ; 95 \% \mathrm{CI}=1.012-2.686 ; \mathrm{P}=0.0445)$ as significant risk factors for the disease. HHV-7 infection was much more common in GD patients $(64.64 \%)$ than in controls $\left(38.73 \% ; \chi^{2}\right.$, $P<0.0001)$, and it increased the risk for GD more than three times $(\mathrm{OR}=3.133 ; 95 \% \mathrm{CI}=1.959-5.011$; $P<0.0001)$. The inheritance of less efficient Pro/Pro TP53 gene variants significantly increased the risk of GD development $(\mathrm{OR}=5.196 ; 95 \% \mathrm{CI}=2.112-12.783 ; P<0.0001)$ and also favored HHV-7 infection $(\mathrm{OR}=2.835 ; 95 \% \mathrm{CI}=1.100-7.310 ; P=0.0275)$. In addition, $72 T P 53$ variants augmented the risk of $\mathrm{GD}$ relapse $(\mathrm{OR}=1.860 ; 95 \% \mathrm{CI}=1.015-3.410 ; \mathrm{P}=0.0446)$.

Conclusions: We suggest that an inherited genetic profile involving TP53 may favor HHV-7 infection and maintenance, which, in turn, may initiate and perpetuate GD autoimmune process.
\end{abstract}

European Journal of Endocrinology 162 315-321

\section{Introduction}

Autoimmune diseases arise as a result of the variable interaction of multiple predisposing genes and nongenetic factors, the latter being predominantly environmental factors.

Infections have long been invoked as an underlying etiology or trigger for the induction of autoimmune thyroid diseases (1-4). There is growing acceptance of a hygiene hypothesis which implies that the immune system is educated by multiple exposures to different infections allowing better controlled autoimmune responses $(5,6)$. It is possible that multiple exposures to infections are necessary to train our immune system to perform well, but some infections are able to break the tolerance of susceptible individuals and allow autoimmune diseases to develop (7). Specific infections could be a triggering factor to disease initiation by liberating antigens (via cell destruction or apoptosis), by forming altered antigens or causing molecular mimicry, by cytokine and chemokine secretion, or by inducing aberrant human leukocyte antigen (HLA)-DR expression and toll-like receptor activation (8).

Human herpesviruses (HHVs) are ubiquitous with widespread tissue tropism and have been found in the thyroid, which can be a reservoir of latent HHVs (9). HHVs have been isolated from $72.22 \%$ of thyroid tissue blocks of patients with Graves' disease (GD) and Hashimoto's thyroiditis (10). HHVs type 6 and type 7 are highly prevalent in the healthy population with a cumulative probability for seropositivity of almost $100 \%$ in young age (11). Like other infectious agents, HHV human antiviral response includes two reciprocal cellular programs: cell survival with the production of protective cytokines and apoptosis for the elimination of infected cells. Tumour protein p53 (TP53) gene plays a major role in the induction of apoptosis or cell cycle arrest in response to genotoxic stress and other types of stress. Much is known about the mechanisms by which viral 
proteins in transformed cells prevent the activities of $\mathrm{p} 53$ (12). During infection, HHV-6B induces significant accumulation of p53 in both the nucleus and cytoplasm, and determines phosphorylation of $\mathrm{p} 53$ at Ser392 (13-15). TP5 3 restricts the production of HHV-6B mRNAs and proteins, which inhibits viral replication and diminishes the cytopathic effects of the virus (16). On the other hand, TP53 may also participate in the autoimmune process since DNA damage and apoptosis may be associated with autoimmune thyroid disease. Anti-p53 antibodies were detected in the sera of $\sim 4 \%$ of patients suspected of having autoimmune thyroid disease (17).

We previously demonstrated that variants of codon 72 (72TP53) and codon 47 of exon 4 of TP53 (which decrease the ability of $\mathrm{p} 53$ to induce apoptosis) increased the risk for HHV-6 infection in renal transplant recipients (18). In addition, we recently demonstrated that a series of codifying genes of detoxification enzymes, including glutathione S-transferase pi 1 (GSTP1) and cytochrome P450, family 1 , subfamily A, polypeptide 1 (CYP1A1), besides $72 T P 53$ polymorphisms, were associated with an increased risk of GD (19). Hence, we aimed to evaluate the relationship among HHV-6 and HHV-7 infections, TP53 apoptotic ability as represented by 72 TP53 polymorphisms, the inherited profile of genes codifying for enzymes involved in the response to xeno- and endobiotics, and GD susceptibility and outcome.

\section{Material and methods}

This prospective case-control study was approved by the ethics committee, and informed written consent was obtained from the 280 GD patients and 284 healthy enrolled individuals. Individuals with a history of previous exposure to specific environmental or occupational risks, such as long-term exposure to solar radiation (more than $4 \mathrm{~h} /$ day for more than 3 days/week) or chemical products (such as pesticides, heavy metals, and organic solvents), and antecedents of autoimmune diseases other than GD were excluded. We also excluded individuals who were taking medications that could interfere with thyroid function evaluation, who came from areas of suspected iodine deficiency, who had a history of radiation exposure, or who had a recent history (2 months) of viral and bacterial infections.

Because ethnicity may influence the rate of HHV infection, we determined skin color, and, in accordance with the Brazilian Institute of Geography and Statistics, classified both patients and controls into white and nonwhite. Cigarette smoking habits were recorded, and both patients and controls were grouped into categories based on smoking history: never smoked and past smoker.

\section{Patients}

Two hundred and eighty Brazilian outpatients with clinical evidence of thyrotoxicosis, diffuse goiter, suppressed serum TSH levels, high serum free thyroxine
$\left(\mathrm{FT}_{4}\right)$, total $\mathrm{T}_{4}$ and triiodothyronine levels, thyrotropin receptor antibody (TRAb), anti-thyroperoxidase (TPOAb), anti-thyroglobulin ( $\mathrm{TgAb}$ ) antibodies, and elevated 24-h radioactive iodine uptake with homogeneous tracer distribution consistent with GD who were previously genotyped for glutathione S-transferase theta 1 (GSTT1), glutathione S-transferase mu 1 (GSTM1), GSTP1, CYP1A1, and TP53 codon 72 were enrolled in the study. Patients were either treated with antithyroid drugs (89 cases with methimazole and 56 cases with propylthiouracil), assigned to radioiodine therapy (133 cases), or assigned to surgery (two cases).

One hundred and ten patients presented with clinical evidence of eye involvement graded with NOSPECS classification as described in Table 1 (20).

In order to investigate the influence of the different genotypes and virus infections on the outcome of the patients, we also evaluated GD patients' response to therapy. Patients were considered in remission when they presented clinical and laboratory evidence of stable euthyroidism or hypothyroidism in the absence of antithyroid drugs at least 12 months (average 17 months) after ${ }^{131}$ I therapy, surgery, or one course or more courses of antithyroid drug therapy discontinuation.

Table 1 Characteristics of the patients. Clinical features of 280 GD patients including gender, ethnicity, smoking history, and degree of eye disease according to NOSPECS classification; laboratory data including autoantibodies anti-thyroperoxidase (TPOAb), anti-thyroglobulin (TgAb), and anti-thyrotropin receptor (TRAb); and type of treatment (antithyroid drugs, therapy, or surgery).

\begin{tabular}{lrc}
\hline & Number of patients & Percentage \\
\hline Gender & & \\
Female & 219 & 78.21 \\
Male & 61 & 21.78 \\
& & \\
Ethnicity & 186 & 66.42 \\
White & & \\
& & \\
Smoking history & 102 & 36.43 \\
Past smoker & & \\
& & \\
Ophthalmopathy & 170 & 60.07 \\
NOSPECS class 0 & 47 & 16.78 \\
NOSPECS class 1 & 37 & 9.21 \\
NOSPECS class 2 & 26 & \\
NOSPECS class 3 & & \\
& & \\
Autoantibodies & 125 & 48.12 \\
TPOAb & 64 & 61.25 \\
TgAb & 98 & 26.25 \\
TRAb & 42 & \\
TPOAb+TgAb+ & & \\
$\quad$ TRAb & & 31.78 \\
Treatment & & \\
Methimazole & & \\
Propylthiouracil & & \\
Radioiodine therapy & & \\
Surgery & & \\
\hline
\end{tabular}




\section{Controls}

We included a control group of 284 healthy individuals selected from the general population of our region, and carefully compared them with the GD patients' group for risk exposure. Individuals who had any history or clinical suspicion of thyroid dysfunction were excluded. Patients and controls were paired upon a physical examination and the data obtained using a structured questionnaire that included questions about demographic and ethnic background; lifetime occupational history; smoking and dietary habits; alcohol, coffee, and drug consumption; physical exercise; drug and medicine use; general health conditions; reproductive history; and previous disease information. Twenty controls were randomly selected from the 284 controls for the evaluation of $\mathrm{TSH} \mathrm{T}_{4}$, and antithyroid antibody levels. All these 20 individuals presented normal thyroid function tests and were negative for thyroid autoantibodies.

\section{Genotypes identification}

HHV-6 was identified using previously described methods of DNA extraction from blood specimens (21). In order to identify HHV-7, we used two sets of nested primers designed to amplify a sequence of the U10 region of this virus (22). A positive HHV-7 control was obtained from a patient with active clinical infection. Positive serological tests and a negative control were included for each of the 16 samples.

GSTT1, GSTM1, GSTP1, CYP1A1, and 72TP53 genotyping was performed using previously described PCR-restriction fragment length polymorphism (RFLP) methods (23-25).

\section{Statistical analysis}

The statistical analysis was conducted using the SAS statistical software version 8.1. Associations were assessed using contingency table analysis; the $\chi^{2}$ or Fisher's (F) exact test was used to examine homogeneity between cases and controls regarding gender, ethnicity, medication use, cigarette smoking habit, and genotypes. The Kruskal-Wallis test was used to compare the ages among the groups. The Mann-Whitney or Wilcoxon test was used to compare the age and goiter size among the different genotype groups. The observed genotype frequencies were compared to those calculated using the Hardy-Weinberg disequilibrium theory. A transmission disequilibrium test calculation was employed to avoid population stratification $(T=0.5193)$. The sample size and power calculations for each gene were calculated using the PS software version 2.1.31. Variables that were significantly associated with GD incidence or outcome by univariate analysis were entered into a multiple logistic regression model in order to evaluate the effect of all genotypes and clinical risk factors, including sex, age, and cigarette smoking as independent predictors. A stepwise regression analysis adjusted for age, gender, and ethnicity was applied to further identify risk factors of GD or Graves' ophthalmopathy. All tests were conducted at the $P=0.05$ significance level.

Since we evaluated associations with multiple genotypes, some associations would appear by chance. To correct for multiple comparisons, we calculated the falsepositive report probability (FPRP) for all associations observed to be statistically significant in the overall analysis or which seemed to differ within subgroups in the stratified analyses using the Excel spreadsheet provided by Wacholder et al. (26). The FPRP depends on the observed result, the prior probability of an association, and the study's power of calculation. The calculations further assume that the power is to detect, under the dominant model, an odds ratio (OR) of 2.0 for each single nucleotide polymorphism (SNP) considering prior probabilities for association with GD according to the values calculated by the software to be noteworthy for each SNP. We considered a FPRP $<0.200$ to indicate a noteworthy association.

\section{Results}

There were no differences found between control individuals and GD patients regarding age (41.1 \pm 16.5 vs $40.8 \pm 12.2$ years), dietary habits, lifetime occupational history, smoking habits, physical exercises, or medical history. However, we were not able to organize a group of patients and controls to compare for all environmental exposure risks that was large enough to guarantee the power of calculation and also to avoid gender and ethnic disparity between the groups. There were more women (219 women - 61 men versus 157 women - 127 men) and fewer Caucasians (186 whites - 94 nonwhites versus 233 whites -51 nonwhites) in the patients group than in the control group $\left(\chi^{2}, P<0.0001\right.$ for both comparisons). As a result, all further statistical comparisons were adjusted for gender and ethnicity.

Clinical characteristics and laboratory features of the patients are resumed in Table 1.

The overall proportion of all genotypes and infected individuals, both in the control population and in the patients group, is presented in Table 2. Through a multivariate logistic regression analysis adjusted for age, gender, and ethnicity, we identified GSTP1, CYP1A1, and $72 T P 53$ variants and the presence of HHV-7 as significant risk factors for GD. The power of calculation for these variants was GSTP1 $=100 \%$, CYP1A1 $=63.8 \%$, and $72 T P 53=48.5 \%$, and all these variant-disease associations remained noteworthy as they presented FPRP values under 0.2 (24). The association between the presence of HHV-7 and GD was very strong (power of calculation $=100 \%$ ) and noteworthy $(\mathrm{FPRP}=0.180)$. 
Table 2 Proportion of GSTM1, GSTT1, GSTP1, and CYP1A1; TP53 polymorphisms; and human herpesviruses (HHV)-6 and HHV-7 among the patients and controls.

\begin{tabular}{|c|c|c|c|c|c|c|c|}
\hline & $\begin{array}{l}\text { GD patients } \\
(n=280) \\
n(\%)\end{array}$ & $\begin{array}{l}\text { Controls } \\
(n=284) \\
n(\%)\end{array}$ & $\begin{array}{l}\text { OR } \\
(95 \% \mathrm{Cl})\end{array}$ & $\boldsymbol{P}$ & $\begin{array}{l}\text { POC } \\
(\%)\end{array}$ & PP & FPRP \\
\hline \multicolumn{8}{|l|}{ GSTM1 } \\
\hline $\begin{array}{l}\text { GSTM1 }+^{a} \\
\text { GSTM1 - }\end{array}$ & $\begin{array}{l}172(63.24) \\
100(35.76)\end{array}$ & $\begin{array}{l}98(57.31) \\
73(42.59)\end{array}$ & $0.829(0.551-1.247)$ & 0.3673 & 31.46 & $<0.25$ & $>0.2$ \\
\hline \multicolumn{8}{|l|}{ GSTT1 } \\
\hline $\begin{array}{l}\text { GSTT1 + }{ }^{\mathrm{a}} \\
\text { GSTT1 }^{-}\end{array}$ & $\begin{array}{l}216(79.41) \\
56(20.59)\end{array}$ & $\begin{array}{l}133(77.78) \\
38(22.22)\end{array}$ & $1.017(0.623-1.660)$ & 0.9462 & 8.14 & $<0.25$ & $>0.2$ \\
\hline \multicolumn{8}{|l|}{ GSTP1 } \\
\hline Ile/lle $e^{a}$ & $112(41.18)$ & $120(70.18)$ & $-^{a}$ & $-^{a}$ & $-^{\mathrm{a}}$ & $-^{a}$ & $-^{a}$ \\
\hline Ile/Val & $131(48.16)$ & $38(22.22)$ & $3.306(2.090-5.229)$ & $<0.0001$ & 99.0 & 0.01 & 0.053 \\
\hline Val/Val & $29(10.66)$ & $13(7.60)$ & $2.374(1.144-4.925)$ & 0.0202 & 18.0 & 0.25 & 0.158 \\
\hline \multicolumn{8}{|l|}{ CYP1A1 } \\
\hline $\mathrm{T} / \mathrm{T}^{\mathrm{a}}$ & $148(55.85)$ & $116(66.29)$ & $-^{a}$ & $-^{a}$ & $-^{a}$ & $-^{a}$ & $-^{a}$ \\
\hline $\mathrm{T} / \mathrm{C}$ & $108(40.75)$ & $53(30.29)$ & $1.597(1.061-2.404)$ & 0.0248 & 57.0 & 0.25 & 0.080 \\
\hline $\mathrm{C} / \mathrm{C}$ & $9(3.40)$ & $6(3.43)$ & $1.176(0.407-3.398)$ & 0.7650 & 5.0 & $<0.25$ & $>0.2$ \\
\hline \multicolumn{8}{|l|}{ 72ТР53 } \\
\hline $\mathrm{Arg} / \mathrm{Arg}^{\mathrm{a}}$ & $127(45.36)$ & 107 (37.68) & $-{ }^{a}$ & $-^{a}$ & $-^{\mathrm{a}}$ & $-^{a}$ & $-^{a}$ \\
\hline Pro/Arg & $116(41.43)$ & $171(60.21)$ & $0.524(0.363-0.756)$ & 0.0006 & 99.0 & 0.01 & 0.089 \\
\hline Pro/Pro & $37(13.21)$ & $6(2.11)$ & $4.379(1.732-11.073)$ & 0.0018 & 99.9 & 0.25 & 0.100 \\
\hline \multicolumn{8}{|l|}{ HHV-6 } \\
\hline HHV-6+ & $36(12.85)$ & $40(14.08)$ & $0.757(0.453-1.266)$ & 0.2893 & 10.84 & $<0.25$ & $>0.2$ \\
\hline \multicolumn{8}{|l|}{$\mathrm{HHV}-7$} \\
\hline HHV-7+ & $181(64.64)$ & 110 (38.73) & 2.907 (2.029-4.164) & $<0.0001$ & 100 & 0.001 & 0.180 \\
\hline
\end{tabular}

Genotypes are considered wild-type (represented in the upper line) or variants (represented in the lower lines) and the statistical comparison includes the false-positive report probability (FPRP) calculations, the power of calculation (POC), and prior probability of an association (PP) obtained by software assuming that power is to detect an odds ratio (OR) of 2.0 (Wacholder et al.) ORs are adjusted for age, gender, and ethnicity.

Bold indicates significant results.

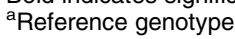

In order to further examine the role of infection with the investigated viruses and other susceptibility factors to GD, we applied a stepwise regression analysis that confirmed the inheritance of GSTP1 variants and CYP1A1 variants as significant risk factors. HHV-6 infection rates were similar in GD patients $(12.85 \%)$ and in controls (14.08\%). However, HHV-7 was much more prevalent among GD patients $(64.64 \%)$ than among controls $(38.73 \%, \quad P<0.001)$. HHV-7 infection increased the risk of developing GD by more than three times $(\mathrm{OR}=3.133 ; 95 \%$ confidence interval $(\mathrm{CI})=1.959-5.011 ; \mathrm{P}<0.0001)$.

In order to further investigate the relationship between autoimmunity and infection rate, we compared the autoantibodies profile of GD patients with and without HHV-7 infection. HHV-7 was demonstrated in $63.5 \%$ of the 259 GD patients with positive thyroid autoantibodies: $50 \%$ of the individuals presenting all three autoantibodies; $61.6 \%$ of the individuals presenting TPOAb; $60.1 \%$ of the individuals presenting $\mathrm{TgAb}$; and $62.24 \%$ of the individuals presenting TRAb. No relationship between HHV-7 infection and any of the investigated thyroid autoantibodies could be established.
Considering that GD occurs more frequently in young adults, we compared the genotypes of patients under and over 25 years of age. A multiple logistic regression analysis adjusted for age, sex, and ethnicity identified the GSTP1 genotype as a risk factor in individuals under 25 years $(\mathrm{OR}=14.726 ; 95 \% \mathrm{CI}=2.689-80.659$; $P=0.0019$ ), while in individuals over 25 years, GSTP1 $(\mathrm{OR}=2.766 ; 95 \% \mathrm{CI}=1.756-4.359 ; \mathrm{P}<0.0001)$, CYP1A1 $\quad(\mathrm{OR}=1.800 ; \quad 95 \% \quad \mathrm{CI}=1.109-2.923$; $P=0.0175), \quad$ Arg $/$ Pro $72 p 53 \quad(\mathrm{OR}=0.506 ; \quad 95 \%$ $\mathrm{CI}=0.337-0.760 ; P=0.0010)$, and Pro/Pro $72 T \mathrm{~T} 53$ $(\mathrm{OR}=3.841 ; 95 \% \quad \mathrm{CI}=1.383-10.667 ; \quad P=0.0098)$ appeared as susceptibility factors to the disease. A stepwise regression analysis confirmed that GSTP1 $(\mathrm{OR}=3.338 ; 95 \% \mathrm{CI}=1.978-5.635 ; P<0.0001)$, CYP1A1 $\quad(\mathrm{OR}=1.812 ; \quad 95 \% \quad \mathrm{CI}=1.055-3.111$; $P=0.0312)$, and HHV-7 $(\mathrm{OR}=3.717 ; 95 \% \quad \mathrm{CI}$ =2.229-6.197; $P<0.0001)$ were significant risk factors for GD among individuals over 25 years.

Eye disease occurred more frequently in male patients $(50.81 \%)$ than in female $(36.74 \%)$ patients $\left(\chi^{2}, P=0.0475\right)$. More than half $(50.50 \%)$ of the patients presenting with ophthalmopathy were smokers 
$\left(\chi^{2}, P=0.0061\right)$. Fewer patients presenting ophthalmopathy $(7.8 \%)$ were also infected with HHV-6 compared to GD patients who did not present with ophthalmopathy $\left(20.28 \% ; \chi^{2}, P=0.0205\right)$. HHV-7 infection rate was similar in patients with $(62.72 \%)$ and without eye disease $(72.89 \%)$. A multiple logistic regression analysis identified smoking $(\mathrm{OR}=1.930 ; 95 \% \mathrm{CI}=1.165-$ 3.197; $P=0.0106$ ) as a factor of susceptibility for eye disease. We were not able to find any relationship between HHV infection, or any of the studied genotypes, and eye disease progression or the outcome of the patients with ophthalmopathy.

Patients presenting the Pro/Pro 72TP53 variant had more than five times the chance of developing GD $(\mathrm{OR}=5.196 ; 95 \% \mathrm{CI}=2.112-12.783 ; \mathrm{P}<0.0001)$ and almost three times the chance of becoming infected with HHV-7 $\quad(\mathrm{OR}=2.835 ; \quad 95 \% \quad \mathrm{CI}=1.100-7.310$; $P=0.0275)$.

Two hundred and eleven patients were considered in remission, while the remaining 54 patients whose hyperthyroidism recurred during the time of observation (32 \pm 7 months) were classified as relapsed. A stepwise logistic adjusted regression analysis identified only $72 p 53$ variants as an important risk factor for $\mathrm{GD}$ relapse $(\mathrm{OR}=1.860 ; 95 \% \quad \mathrm{CI}=1.015-3.410$; $P=0.0446)$.

\section{Discussion}

We previously demonstrated that individuals with GSTP1 and CYP1A1 variants may be more susceptible to the effect of autoimmunity-inducing environmental or endogenous products (19). Pro72TP53 homozygous inheritance was revealed as an important risk factor of GD, especially among smokers (19). Using a subset of $280 \mathrm{GD}$ patients carefully paired for exposure to environmental risk factors with a control group of 284 individuals, we confirmed the data and now demonstrate that HHV-7 infection is also associated with an increased susceptibility to GD. We suggest that HHV-7 may be taking advantage of the poorer apoptotic ability of $72 T P 53$ variants to trigger the autoimmune process that leads to GD.

TP53 gene plays a key role in the protection of host cells against viral infection and antiviral immune response (27). Polymorphisms of TP53 have been implicated in the development of a series of malignancies associated with viral infection (28-30), thyroid cancer (31), and some autoimmune diseases (32, 33). A recent investigation reported an increased frequency of the Arg/Arg homozygous genotype for the TP53 codon 72 in 107 Hashimoto's thyroiditis patients as compared with 105 control Chinese individuals, but failed to observe any statistically significant difference concerning allelic or genotypic analysis for 90 GD patients (34). Genetic profiles exhibit important ethnic and geographic frequency variations that may account for part of the inconsistent results reported by most studies (35). Our data suggest that this polymorphism may be implicated not only in the initiation, but also in the perpetuation of the disease since 72 TP53 polymorphisms were associated with GD outcome.

Herpesvirus infection might be involved in the pathophysiology of several chronic autoimmune inflammatory processes $(36,37)$. Herpes infection potentially increases the efficiency of $\mathrm{T}$ cell activation through enhanced expression of co-stimulatory molecules, up-regulation of HLA expression on specialized antigen-presenting cells, and attraction of dendritic cells from peripheral to secondary lymphoid tissues. Continued activation of innate immunity against herpesvirus infection can also potentiate immune disorders.

In autoimmune thyroid disease, increased apoptosis has been proposed as one of the main mechanisms for both thyroid cell and infiltrating T cell programmers' death (38). HHV-infected $\mathrm{CD}^{+}$lymphocytes display increased surface expression of tumor necrosis factor 1 , resulting in apoptosis $(39,40)$. The inheritance of less efficient TP53 genes significantly increases the risk of GD development and also favors HHV-7 infection and perpetuation, which, in turn, may initiate and perpetuate the autoimmune process in GD. However, we still lack evidence of the direct effect of herpes infection on thyroid cells. The detection of viral sequences in peripheral blood mononuclear cells may just reflect a higher viral load in the blood of these subjects and not an active infection. Alternatively, positive subjects may have a higher proportion of circulating $\mathrm{CD}^{+} \mathrm{T}$ cells, which are believed to be the main reservoir of HHV-6 and HHV-7 in blood. The correlation between HHV PCR and CD4 counts should be investigated, as well as the correlation between HHV-6 positivity and HHV-7 positivity.

\section{Conclusion}

Our data suggest that herpesvirus type 7 infection plays an important role in individuals with a genetic profile of susceptibility to GD. Consortia and international collaborative studies are necessary in order to overcome the limitations of our data and to further enlighten the multifaceted scenery of environmental risk factors for thyroid autoimmune diseases and genetic variations. Elucidation of the underlying mechanisms involved in this complex relationship may allow for the development of new etiologically based therapeutic modalities.

\section{Declaration of interest}

We declare that there is no conflict of interest that could be perceived as prejudicing the impartiality of this study reported. 


\section{Funding}

This study was supported by the State of São Paulo Research Foundation (FAPESP) and the National Council for Scientific and Technological Development $(\mathrm{CNPq})$ under the grant numbers 06/01651-1 and 470317/2006-0 respectively.

\section{References}

1 Desailloud R \& Hober D. Viruses and thyroiditis: an update. Virology Journal 2009125.

2 Lehmann HW, Lutterbüse N, Plentz A, Akkurt I, Albers N, Hauffa BP, Hiort O, Schoenau E \& Modrow S. Association of parvovirus B19 infection and Hashimoto's thyroiditis in children. Viral Immunology 200821 379-383.

3 Thomas D, Karachaliou F, Kallergi K, Vlachopapadopoulou E, Antonaki G, Chatzimarkou F, Fotinou A, Kaldrymides P \& Michalacos S. Herpes virus antibodies seroprevalence in children with autoimmune thyroid disease. Endocrine 200833 171-175.

4 Tozzoli R, Barzilai O, Ram M, Villalta D, Bizzaro N, Sherer Y \& Shoenfeld Y. Infections and autoimmune thyroid diseases: parallel detection of antibodies against pathogens with proteomic technology. Autoimmunity Reviews 2008 8 112-115.

5 Bach JF. Infections and autoimmune diseases. Journal of Autoimmunity 200525 74-80.

6 Bloomfield SF, Stanwell-Smith R, Crevel RW \& Pickup J. Too clean, or not too clean: the hygiene hypothesis and home hygiene. Clinical and Experimental Allergy 200636 402-425.

7 Davies TF. Infection and autoimmune thyroid disease. Journal of Clinical Endocrinology and Metabolism 200893 674-675.

8 Harii N, Lewis CJ, Vasko V, McCall K, Benavides-Peralta U, Sun X, Ringel MD, Saji M, Giuliani C, Napolitano G, Goetz DJ \& Kohn LD. Thyrocytes express a functional toll-like receptor 3: overexpression can be induced by viral infection and reversed by phenylmethimazole and is associated with Hashimoto's autoimmune thyroiditis. Molecular Endocrinology 200519 1231-1250.

9 Chen T \& Hudnall SD. Anatomical mapping of human herpesvirus reservoirs of infection. Modern Pathology 200619 726-737.

10 Thomas D, Liakos V, Michou V, Kapranos N, Kaltsas G, Tsilivakos V \& Tsatsoulis A. Detection of herpes virus DNA in post-operative thyroid tissue specimens of patients with autoimmune thyroid disease. Experimental and Clinical Endocrinology $\mathcal{E}$ Diabetes 2008 $11635-39$.

11 Krueger GR, Koch B, Leyssens N, Berneman Z, Rojo J, Horwitz C, Sloots T, Margalith M, Conradie JD, Imai S, Urasinski I, de Bruyère $M$, Ferrer Argote $V$ \& Krueger J. Comparison of seroprevalences of human herpesvirus- 6 and -7 in healthy blood donors from nine countries. Vox Sanguinis 199875 193-197.

12 Harris SL. The p53 pathway: positive and negative feedback loops. Oncogene $2005 \mathbf{2 4} 2899-2908$.

13 Takemoto M, Mori Y, Ueda K, Kondo K \& Yamanishi K. Productive human herpesvirus 6 infection causes aberrant accumulation of p53 and prevents apoptosis. Journal of General Virology 200485 869-879.

14 Øster B, Bundgaard B \& Höllsberg P. Human herpesvirus 6B induces cell cycle arrest concomitant with p53 phosphorylation and accumulation in $\mathrm{T}$ cells. Journal of Virology $2005 \mathbf{7 9}$ 1961-1965.

15 Oster B, Bundgaard B, Hupp TR \& Höllsberg P. Human herpesvirus $6 \mathrm{~B}$ induces phosphorylation of p53 in its regulatory domain by a CK2- and p38-independent pathway. Journal of General Virology $20088987-96$.

16 Oster B, Kofod-Olsen E, Bundgaard B \& Höllsberg P. Restriction of human herpesvirus 6B replication by p53. Journal of General Virology 200889 1106-1113.

17 Fenton CL, Patel A, Tuttle RM \& Francis GL. Autoantibodies to p53 in sera of patients with autoimmune thyroid disease. Annals of Clinical Laboratory Science 200030 179-183.
18 Leite JL, Manfrinatto JA, Mazzali M \& Ward LS. Polymorphisms at exon 4 of p53 and the susceptibility to herpesvirus types 6 and 1 infection in renal transplant recipients. Transplant International $200619732-737$.

19 Bufalo NE, Santos RB, Cury AN, Andrade RA, Morari J, Morari EC, Leite JL, Monte O, Romaldini JH \& Ward LS. Genetic polymorphisms associated with cigarette smoking and the risk of Graves disease. Clinical Endocrinology 200868 982-987.

20 Werner SC. Modification of the classification of the eye changes of Graves' disease: recommendations of the Ad Hoc Committee of the American Thyroid Association. Journal of Clinical Endocrinology and Metabolism 197744 203-204.

21 Leite JL, Stolf HO, Reis NA \& Ward LS. Human herpesvirus type 6 and type 1 infection increases susceptibility to nonmelanoma skin tumors. Cancer Letters $2005 \mathbf{2 2 4} 213-219$.

22 Chan P, Chan M, Li W, Chan D, Cheung J \& Cheng A. Association of human $\beta$-herpesviruses with the development of cervical cancer: bystanders or cofactors. Journal of Clinical Pathology 200154 48-53.

23 Morari EC, Leite JL, Granja F, Assumpcao LVM \& Ward LS. The null genotype of glutathione S-transferase M1 and T1 locus increases the risk for thyroid cancer. Cancer Epidemiology, Biomarkers $\mathcal{E}$ Prevention 200211 1485-1488.

24 Bufalo NE, Leite JL, Guilhen AC, Morari EC, Granja F, Assumpção LVM \& Ward LS. Smoking and susceptibility to thyroid cancer: an inverse association with CYP1A1 allelic variants. Endocrine-Related Cancer 200613 1185-1193.

25 Morari EC, Lima AB, Bufalo NE, Leite JL, Granja F \& Ward LS. Role of glutathione-S-transferase and codon 72 of P53 genotypes in epithelial ovarian cancer patients. Journal of Cancer Research and Clinical Oncology 2006132 521-528.

26 Wacholder S, Chanock S, Garcia-Closas M, El Ghormli L \& Rothman N. Assessing the probability that a positive report is false: an approach for molecular epidemiology studies. Journal of the National Cancer Institute 200496 434-442.

27 Muñoz-Fontela C, Garcia MA, Garcia-Cao I, Collado M, Arroyo J, Esteban M, Serrano M \& Rivas C. Resistance to viral infection of super p53 mice. Oncogene 200524 3059-3062.

28 Yoon YJ, Chang HY, Ahn SH, Kim JK, Park YK, Kang DR, Park JY, Myoung SM, Kim do Y, Chon CY \& Han KH. MDM2 and p53 polymorphisms are associated with the development of hepatocellular carcinoma in patients with chronic hepatitis B virus infection. Carcinogenesis 200829 1192-1196.

29 Bhattacharya P \& Sengupta S. Predisposition to HPV16/18related cervical cancer because of proline homozygosity at codon 72 of p53 among Indian women is influenced by HLA-B*07 and homozygosity of HLA-DQB1*03. Tissue Antigens $2007 \mathbf{7 0}$ 283-293.

30 Pantelis A, Pantelis D, Ruemmele P, Hartmann A, Hofstaedter F, Buettner R, Bootz F \& Stoehr R. p53 Codon 72 polymorphism, loss of heterozygosity and high-risk human papillomavirus infection in a low-incidence German esophageal squamous cell carcinoma patient cohort. Oncology Reports 200717 1243-1248.

31 Granja F, Morari J, Morari EC, Correa LA, Assumpção LV \& Ward LS. Proline homozygosity in codon 72 of p53 is a factor of susceptibility for thyroid cancer. Cancer Letters $2004 \mathbf{2 1 0}$ 151-157.

32 Piotrowski P, Lianeri M, Mostowska M, Wudarski M, ChwalinskaSadowska H \& Jagodzinski PP. Contribution of polymorphism in codon 72 of p53 gene to systemic lupus erythematosus in Poland. Lupus 200817 148-151.

33 Macchioni P, Nicoli D, Casali B, Catanoso M, Farnetti E, Boiardi L \& Salvarani C. The codon 72 polymorphic variants of p53 in Italian rheumatoid arthritis patients. Clinical and Experimental Rheumatology 200725 416-421.

34 den Reijer PM, Maier AB, Westendorp RG \& van Heemst D. p53 codon 72 proline/arginine polymorphism and autoimmune thyroid diseases. Journal of Clinical Laboratory Analysis 200822 321-326. 
35 Garte S. Metabolic susceptibility genes as cancer risk factors: time for a reassessment? Cancer Epidemiology, Biomarkers \& Prevention 200110 1233-1237.

36 Scotet E, Peyrat MA, Saulquin X, Retiere C, Couedel C, Davodeau F, Dulphy N, Toubert A, Bignon JD, Lim A, Vie H, Hallet MM, Liblau R, Weber M, Berthelot JM, Houssaint E \& Bonneville M. Frequent enrichment for CD8 $\mathrm{T}$ cells reactive against common herpes viruses in chronic inflammatory lesions: towards a reassessment of the physiopathological significance of $\mathrm{T}$ cell clonal expansions found in autoimmune inflammatory processes. European Journal of Immunology 199929 973-985.

37 Posnett DN. Herpesviruses and autoimmunity. Current Opinion in Investigational Drugs 20089 505-514.
38 Fountoulakis S \& Tsatsoulis A. On the pathogenesis of autoimmune thyroid disease: a unifying hypothesis. Clinical Endocrinology 2004 $60397-409$.

39 Inoue $\mathrm{Y}$, Yasukawa $\mathrm{M} \&$ Fujita S. Induction of T-cell apoptosis by human herpesvirus 6. Journal of Virology 1997 71 3751-3759.

40 Ito T. Overexpression of bcl-2 suppresses apoptosis in the human leukemia cell line TF-1. Rinsho Byori. The Japanese Journal of Clinical Pathology 199745 628-637.

Received 3 November 2009

Accepted 5 November 2009 